\title{
STRATEGIC POSITIONING OF EAP IN SOUTH AFRICAN WORKPLACES
}

\author{
MG Matlhape (Wits Health)
}

\begin{abstract}
Two phenomena are having a profound effect on management and industry in the $21^{\text {st }}$ century. The first one is the increasing rate and depth of competition locally, regionally, and globally, and the consequent increase in focus on achieving competitiveness by companies. The second phenomenon is the increasing appreciation of the importance of employees in assisting the company to gain a competitive advantage over its competitors.
\end{abstract}

Employee Assistance Programmes have been used as part of the business strategy to enhance employee functioning, loyalty, and performance in organisations around the world for a good part of the $20^{\text {th }}$ century. In South Africa this service did not gain much momentum until the 1980. Despite the growth of EAP in South Africa, however, in most cases it still remains on the periphery of real business activities and is often regarded as a "nice to have" rather than as a business imperative.

The location of EAP within a company is very important in determining its impact within the organisation. Because of EAPs capacity to impact on both individual employees and the organisation as its primary client, it has potential to make a great impact in organisations' business processes, where these interface with individual output and wellbeing.

A service-profit-chain model was introduced as a link between employee satisfaction and company profitability. This article gives an in-depth focus on EAP and the important role it can play in achieving employee satisfaction.

Keywords: EAP, Employee Assistance Programmes, strategic positioning

\section{INTRODUCTION}

The connection between business success and customer care has been acknowledged for many years, but very few oganisations have so far had the vision to apply this caring philosophy holistically to include employees and other stakeholders equally. Positive stress (eustress) in the form of constant challenges at work is an essential element of employee motivation and job satisfaction. It is when the level and depth of work generated stress becomes negative (distress) that intervention is indicated.

Employee Assistance Programmes (EAP) have existed for many decades as work based employee support programmes designed to assist employees who are experiencing work related and unrelated problems. This article will present an overview of EAP, what it is and its historical evolution from the turn of the century to the present. Focus will then be given to 
the broad spectrum of models for the philosophy and values underpinning EAP in companies.

EAP struggles to entrench itself within the business environment, and that could be because it remains outside the realm of what is important in business, namely profit. The paper will conclude with an examination of how EAP can be used to facilitate the achievement of business objectives, in particular, service excellence, continuous improvement and total quality management.

\section{OVERVIEW AND DESCRIPTION OF EAP}

In many organisations, there are employees who exhibit, among other things, decreasing productivity, increasing absenteeism, rising lateness, violence as well as alcohol and drug use in the workplace. The causes of these behaviours are often not understood or investigated, resulting in losses for both employee and employer (Maeli 1999:2). EAP present an opportunity to manage such problems in a way that will result in retention of talented employees and improvement of employer-employee relationships.

EAPA-SA (1999:5) defines EAP as a work-site based programme designed to assist in the identification and resolution of productivity problems associated with employees impaired by personal concerns but not limited to health, marital, family, financial, alcohol, drug, legal, emotional, stress, or other personal concerns which may adversely affect employee job performance.

Employee assistance programmes are specifically designed to identify and assist employees and their families with various difficulties that impair personal and occupational functioning, as well as designed to improve employer-employee communication and create a positive atmosphere within the work environment (Ramakrishnan \& Balgopal 1992:4).

According to EAPA-SA (1999:5-6), the core activities of EAP include the following:

- Consultation and training to appropriate persons in the identification and resolution of job performance issues related to employees personal concerns and difficulties;

- Confidential, appropriate, relevant, and timely problem assessment services;

- Appropriate and relevant referrals for diagnosis, treatment and assistance;

- The formation of linkages between work-site EAP, community resources and individual practitioners who provide such services;

- Follow up services for employees who utilise these services.

In her research on the nature of EAPs in South Africa, Harper (1999:13) discovered that South African EAPs tend to give a dual focus to the organisation and employees as the 
primary client and have as a result been responsive to modern day organisational issues affecting employees at work. These include transformation, affirmative action, downsizing, HIV and Aids, and sexual harassment.

Companies use various service models for the provision of EAP services. These include:

- Employment of EAP specialists to offer an internal EAP service

- Employment of a coordinator to act as a conduit for the referral of employees requiring EAP services to external resources.

- Complete outsourcing of EAP to an external service provider.

There are advantages and disadvantages to each one of these models, and therefore the choice of structure within which the EAP must be provided depends entirely on the organisation, namely its structure, position in industry, business strategies and priorities.

\section{POSITIONING OF EAP SERVICES IN ORGANISATIONS}

EAP services are a component of the workplace because of the key role they play in enhancing productivity and improving profitability. Because of this, EAP should be regarded as a strategic issue and therefore be located in the core strategies of the business. In order for EAP to deliver the intended results, there must be a mechanism to make it accessible anywhere in the company where employee wellbeing needs to be enhanced. In this way, EAP will help to produce strategic responses that can help to advance organisational goals towards achieving total quality. The following section focuses on the various areas of organisational functioning where EAP can be located.

\section{EAP as a component of Occupational Health and Safety}

Most companies already have divisions that focus exclusively on occupational health and safety (OHS). OHS usually exists in manufacturing companies where there are health hazards and appropriate legal standards that have to be adhered to in order to minimise risk. Most OHS departments employ medical personnel who focus on managing the effect of the physical work environment on the health and wellbeing of employees.

Many studies conducted about health and performance at work identify occupational stress as being an important consideration at all levels of seniority in the workplace (Cooper \& Payne 1988; Wolf \& Finestone 1986; Muldoon 1998). Stress as an occupational health hazard is therefore increasingly directing organisations to focus their OHS not only on curative physical health care and disability, but to also explore preventative programmes that will result in enhanced work performance.

Before 1999, the attention of OHS was on managing health care to prevent accidents at work as well as on boarding employees who have become disabled due to accidents at work and outside work. While this is still the case concerning the prevention of accidents, the 
Employment Equity Act's recognition of the right of disabled people to employment will have a great impact on the functions of OHS units. As companies employ more disabled people, support programmes have to be put in place to ensure that they achieve maximum productivity and quality output without any risk to their own occupational health and safety. This support will range from ensuring the physical accessibility of buildings to educating management about the management of mental disabilities in the workplace. In either case, an opportunity exists for EAP services to help organisations to achieve a balance between adhering to legal requirements and improving or maintaining quality standards within the organisation.

In her research involving the top 100 companies in South Africa, Harper (1999:4) identified that of the 42 companies who have EAP services, $45 \%$ were located in Occupational Health. This unfortunately tends to give EAP a health and health promotion focus to the exclusion of other broader organisational development issues affecting employees.

\section{EAP as an employment benefit}

Employers have long been involved with the health and wellbeing of their employees. Most employers are purchasers of health and benefit insurance, many provide medical services and health promotion activities at the worksite (Mabe 1999:25).

In her research, linking EAP as a response to job dissatisfaction among employees, Mabe (1999:25-6) identified that EAP is not likely to be an incentive to a prospective employee, but that for the incumbent employees it is often regarded as an additional benefit associated with the fulfilment of the following objectives for the company:

- Increasing employee morale

- Reducing staff turnover

- Increasing job satisfaction

- Motivating employees

- Enhancing the organisation's image among employees

- Making better use of compensation dollars

- Keeping the union out.

Most people feel depressed when they experience a breakdown in their relationships or suffer disappointment; similarly, when the pressures of work or family life build up, so too does anxiety (Lynch 1998:200). Offering EAP services for employees experiencing these problems is an important benefit and can enhance the image of the organisation to its employees. EAP, therefore, has a direct impact on the level of employee satisfaction and thus on the value an employee can produce in the company. This would translate into value for the company's customer, resulting in their increasing loyalty to the company (Heskett et al. 1997:11).

EAP services can also fulfil the additional benefit objective through the access of employees' families to the service. In cases where the stressors identified in the employee's life are 
family related or affects the family as well, e.g. a divorce or HIV status, counselling and support to the employee without his or her family would be inadequate.

\section{EAP as part of a caring organis ational culture}

Throughout the twentieth century, in fact, since the first industrial revolution in the eighteenth century, corporate success and value has been measured in terms of financial capital: the plant, materials, and cashflow which can be easily identified and assigned a monetary value. With the arrival of the Information Revolution in more recent years, intellectual capital has joined finance as a determinant of success and an additional indicator of total worth. The melding of financial and intellectual capital is recognised as providing the sinews of competitive strength. However, the power to win on any battlefield does not rely on physical prowess alone: success can depend on the exercise of psycho-spiritual sensitivities (Lynch 1998:2).

Compassion for employees is part of this emotional capital upon which goodwill among stakeholders can be based. As already stated elsewhere in this work, the most difficult goodwill to cultivate is the one between employees and the employer. This is the concept of employee loyalty. According to Lynch (1998:134), loyalty is closely linked to the trust that employees have in their companies. However, there is growing evidence that workers are becoming sceptical about a company's trustworthiness. As the rature of the employer/ employee relationship is redefined, giving greater importance to the centrality of human resources in companies, the role of the employer in caring for the wellbeing of the employee becomes even more important.

The elevation of employees as a recognised part of a corporation's capital portfolio in recent years has highlighted the need to give more attention to their wellbeing in a similar manner that other company assets are maintained.

In the same way, that emotional intelligence has become a recognised leadership quality, emotional capital is also a recognised value of collective emotional intelligence in a company. EAP is one programme that a company can use to communicate this compassion to its employees and be able to capitalise on its value as enhancing the company's image. In her research into the relationship between job satisfaction and EAP services, Mabe (1999) found a clear correlation, leading to a conclusion that EAP is central to creating employee and customer loyalty.

\section{EAP as Social Responsibility}

There is no doubt that there is an escalation of distress among South Africans because of, among other things, a breakdown in relationships or an increase in family and work pressures on people. In the recent past, those for whom these negative feelings were acute and long term were often held in institutions separated from their healthier compatriots. Now 
for a variety of medical and socio-economic reasons, they live increasingly in communities forming an integral part of the labour force and customer base for companies.

Good corporate citizenship will involve companies extending EAP programmes to include their employees' families and immediate communities. This would not be regarded as EAP, as it has no direct bearing on improving work performance. However, it could provide essential resources for employees, which could be of benefit to general employee wellbeing.

According to Harper (1999:12), historically many EAP's in South Africa were implemented in the 1980 s by corporations as a means of demonstrating internal social responsibility towards their employees, especially with respect to disadvantaged employees whose community psychosocial resources were almost non-existent. "This has been a double edged sword for EAP services and practitioners in that the positioning of EAP's as primarily a part of social responsibility means that in times of cutbacks, EAP's have short-sightedly often been seen as a convenience rather than an integral part of the business" (Harper 1999:12).

\section{EAP as part of the business strategy}

An organisation's strategy consists of the actions and business approaches management employs to achieve the targeted organisational performance (Thompson \& Strickland 1999:5). It is a product of constant industry and competitor analysis, matched with the organisation's resource strengths and weaknesses as well as competitive capabilities and deficiencies. A key analytical tool used extensively in this instance is Porter's Five Forces Model of Competition, presented hereunder as figure 1.1.

Good understanding of these forces as they influence the company is imperative for EAP professionals as they can help mobilise more value from the company's human resources, thereby giving the company a competitive advantage over its rivals.

The role of EAP would be to stay vigilant of emerging personal and environmental factors that may affect employee well-being, and assist the company to manage these proactively, so that they do not weaken the company's competitive position. In the case of South Africa, this strategic intervention would include assisting the company to plan proactively for the threat of HIV and Aids and its impact on human resources management broadly.

Similarly, EAP professionals would be well placed to intervene in helping a product-focused company transform to being a total quality management practising company. In this instance, the EAP's strength would be particularly useful in facilitating relationship building between the company and its employees, as well as within different teams. 
Figure 1.1 PORTER'S FIVE-FORCES MODEL OF COMPETITION

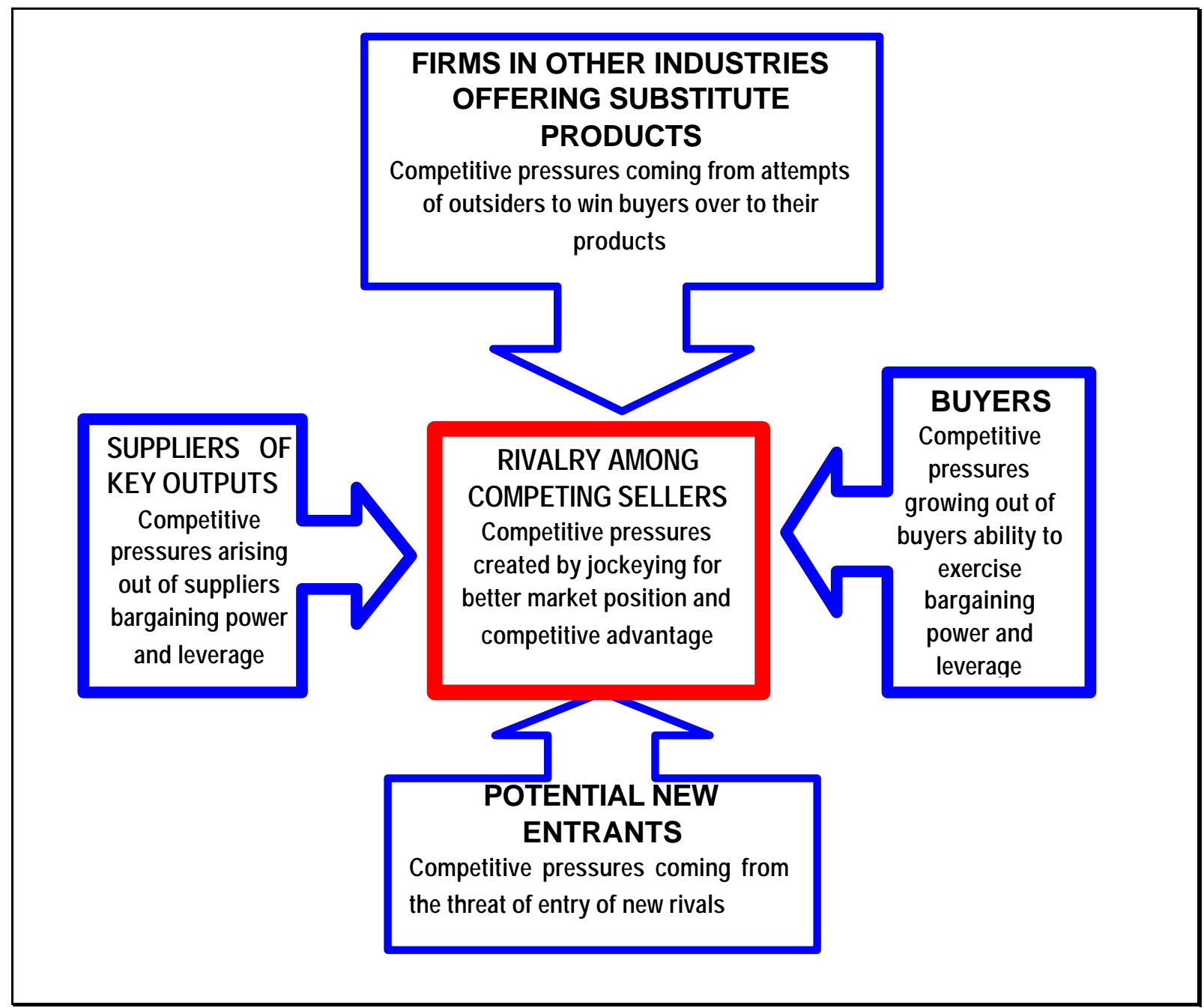

Source: Thompson \& Strickland 1999:75

It has been mentioned repeatedly throughout this text that companies are increasingly acknowledging human resources as their most essential resource and as a source of competitive advantage. Because of this, Pennington (2001:3) advices that one of the challenges of the $21^{\text {st }}$ century for human resources management is that human resource departments will be looked upon to take on a more active role as custodians of company strategies. One of the key functional areas of the HR strategy for the $21^{\text {st }}$ century is EAP, and therefore active collaborating of EAP and HR is essential.

Coppersmith (1995:30) suggests that EAP should position itself as a central theme within $H R$, influencing all HR functions in the organisation. This centrality is depicted in figure 1.2. The diagram depicts both the central role that EAP can play in the human resources management, as well as its bridging role between each of the other HR functional areas. 
In particular, EAP professionals are in a unique position to encourage organisational development. They have the greatest access to the widest variety of employees in the least authoritarian manner of anyone in the entire company (Du Plessis 1992:3).

There is no doubt that there is inadequate understanding and use of EAP in South African workplaces. This results in inadequate sensitivity to employees' problems and stress inducing difficulties, whether work related or unrelated. The responsibility rests with both management and EAP professionals to change the status quo, and promote the use of EAP. A number of priorities for the successful use of EAP emerge as follows:

- Productivity must be seen as a strategic issue for South African companies. This paradigm change will facilitate the use of productivity enhancing solutions, like EAP, strategically and communicating company leadership commitment to such practises.

- Companies' use of EAP should be based on an informed set of expectations, which will have an impact in the strategic objectives of the company. The focus of management with the use of EAP should not only be to meet the organisations' business objectives, but to achieve optimal utilisation of organisational resources (factors of production) namely, capital employed, company assets or equipment, as well as human beings.

- EAP systems have to stop being reactionary in focus, and develop a preventative and facilitative role. Reactionary or treatment focus has a tendency of developing a stigma against those who are identified as needing counselling and support from EAP, whereas the facilitative focus can be used to transform the organisational culture as a whole to a more caring and supportive one.

- There is room in most organisations for EAP to be positioned in OHS, social responsibility, and as a component of human resource benefits. This situation may work for most companies, but will unfortunately not lead to optimal benefit from EAP. EAP is an organisational development function, and should therefore be positioned as a central ethos to all human resource management functions in an organisation.

- EAP professionals often contribute in "sabotaging" EAP within organisations. For them to be able to respond to, and anticipate EAP needs within a company, there is a need for EAP professionals to be aware of the forces of competition affecting the company. This awareness will facilitate their ability to support the company and its employees in a manner that really matters to the company.

The success of EAP also depends on its acceptance by labour union representatives within the company. The traditional adversarial relationship between employers and labour unions may lead to failure of acceptance of EAP by employees. An important standard for all EAP services in South Africa, as developed by EAPA-SA $(1999: 11)$ is that a workplace EAP council with representatives from management, employees, and recognised labour unions in the company be established. This council ensures that the EAP service does not develop a 
bias in favour of management nor employees, as well as to ensure that the needs of all stakeholders are adequately met.

\section{Figure 1.2 EAP and HR Partnering}

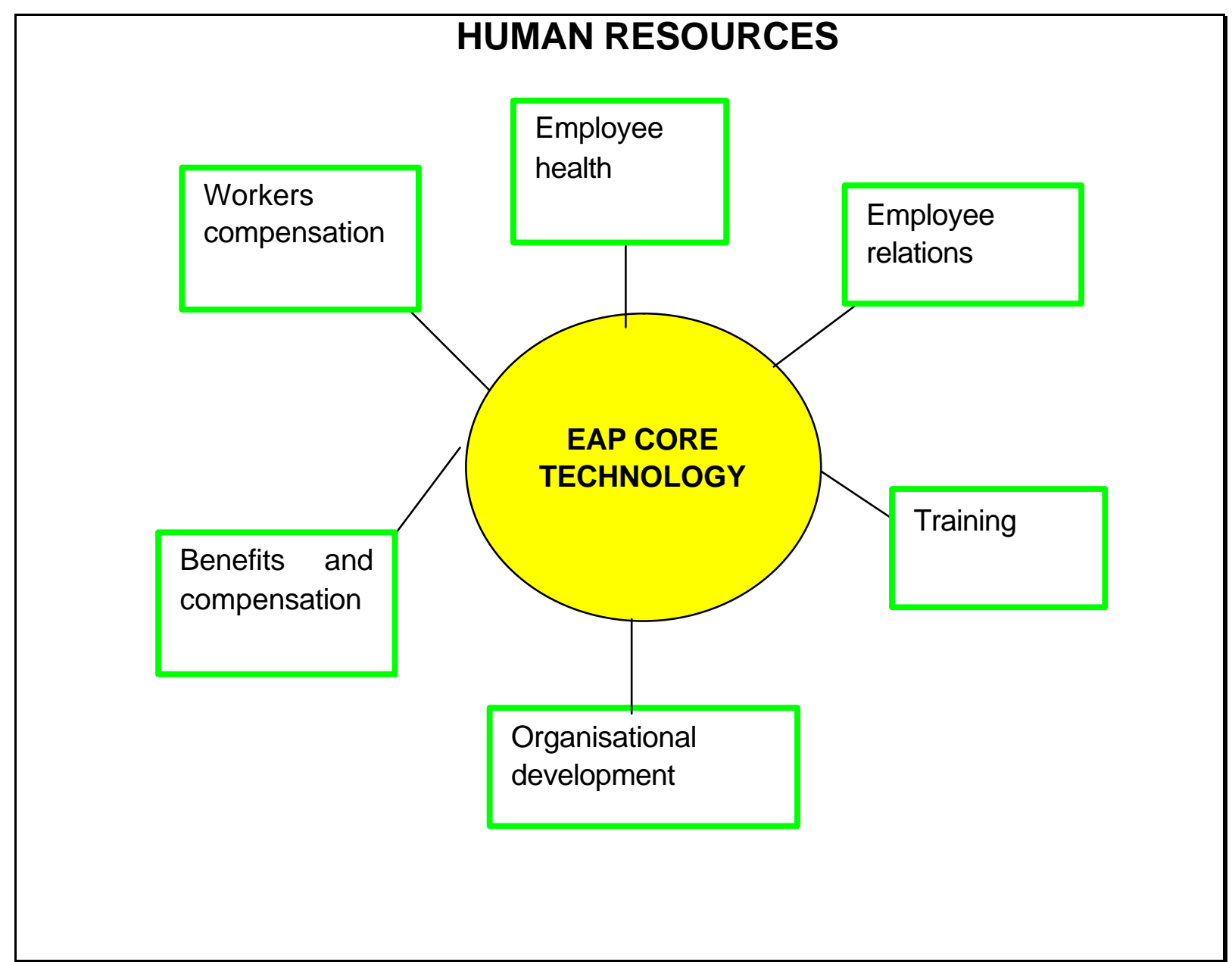

Source: Coppersmith 1995:30

\section{CONCLUSION}

Employee Assistance Programmes have evolved a great deal since their inception as treatment based services focusing on problem employees, especially those suffering from alcohol and drug dependence. EAP's strength in "healing" individuals and broken relationships can be transferred effectively to enhance organisations' benefits from their human resources investments. EAP is also well placed to build relationships within different teams as well as between teams, in order to facilitate alliance in the quest for achieving organisational objectives. 
Not surprisingly, EAP has remained largely on the periphery of business, largely being under-utilised within companies. A major factor in this situation is that EAP has tended to be located in non-strategic components of business activities. An EAP challenge for the $21^{\text {st }}$ century is to position itself as a strategic resource within the workplace to help companies maximise employee productivity and retention.

\section{BIBLIOGRAPHY}

COOPER CL \& PAYNE R. 1988. Causes, coping and consequences of stress at work. Chichester : Wiley.

COPPERSMITH L. 1995. EAP-HR partnering. EAP Digest: 30-32, January-February.

DU PLESSIS A. 1992. Employee Assistance Programmes in South Africa. EAP International, October.

EAPA-SA . 1999. Standards for Employee Assistrance Programmes: from micro to macro practice. EAP's in practice in the South African context: 2-6.

HARPER T. 1999. Employee Assistance Programming and professional developments in South Africa. Employee Assistance Quarterly, 14(3): 1-18.

HESKETT JL, JONES TO, LOVEMAN GW, SASSER WE \& SCHLESINGER LA. 1997. Putting the serviceprofit chain to work. Harvard Business Review: 164-173, March-April.

LYNCH JJ. 1998. Corporate compassion: succeeding with care. London : Cassell.

MABE CM. 1999. The importance of a job satisfaction investigation for the development of an Employee Assistance Program. Johannesburg: Rand Afrikaans University. [MADissertation.]

MAELI VJ. 1999. A need analysis for an Employee Assistance Program. Johannesburg: Rand Afrikaans University. [MADissertation.]

MULDOON Y. 1998. Stres, gesondheid, afwesighede en ongelukke in organisasies. Johannesburg: Randse Afrikaanse Universiteit. [PhD-proefskrif.]

RAMAKRISHNAN KR \& BALGOPAL PR. 1992. Linking task-centred intervention with Employee Assistance Programs. Families in Society, 73(1):488-94.

THOMPSON AA \& STRICKLAND AJ. 1999. Strategic Management: concepts and cases. $11^{\text {th }}$ ed. Singapore : Irwin McGraw-Hill.

WOLF SG \& FINESTONE AJ. 1986. Occupational stress: health performance at work. Massachusetts: PSG. 